
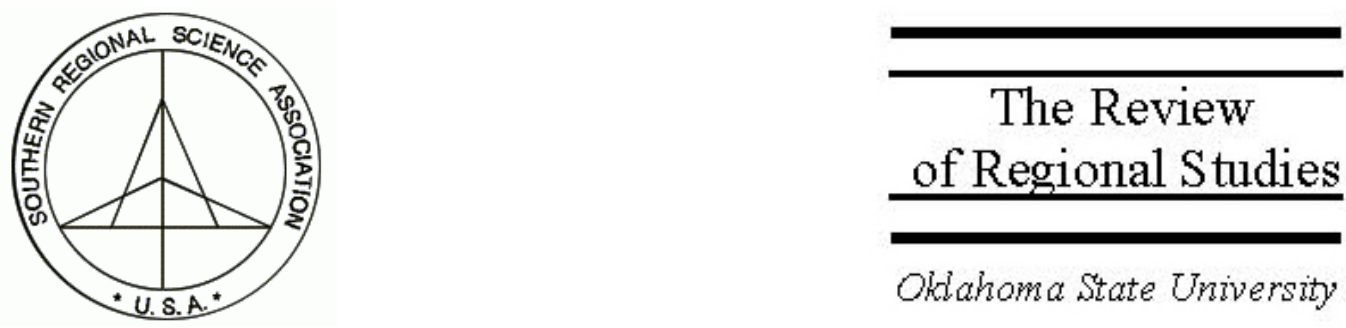

\title{
Understanding Regional Growth
}

\author{
Vincenzo Spiezia \\ Directorate for Science, Technology and Industry, Organization for Economic \\ Cooperation and Development (OECD), Paris, France, \\ e-mail: vincenzo.spiezia@oecd.org \\ Stephan Weiler \\ Department of Economics, Colorado State University, Colorado Spring, CO, \\ e-mail:stephan.weiler@colostate.edu
}

\begin{abstract}
We explore the variations in regional economic growth within 26 countries relative to the OECD norm between 1998 and 2003. This analysis sheds light on the role of regions in determining national growth patterns, while also providing a method similar to shift-share that can assess the relative importance of a range of demographic and economic factors in driving such growth. In particular, this taxonomy isolates those growth factors involving region-specific assets that are potentially most influenced by policy. In this sense, the findings help highlight policy niches that can most effectively shape regional growth prospects while also challenging traditional views of regional growth drivers.
\end{abstract}

Keywords: Regional Growth; Growth Decomposition; OECD

JEL classification: R11; R58; O47 


\section{INTRODUCTION}

Most analyses of national economies focus on broad national indicators. Unemployment, gross domestic product, the inflation rate-all are traditionally used as gauges of the health of the macroeconomy. Two consecutive quarters of negative GDP growth is generally considered the benchmark for a recession. High unemployment signals labor market difficulties for all workers.

Yet such broad measures may hide significant variations in economic performance within a given national economy. National economies represent the geographical aggregation of different regional economies, each of which may differ considerably in their economic fortunes. High local growth in some areas may lie in stark contrast to longerterm stagnation difficulties in other areas. Low local unemployment suggests some labor markets are thriving, but joblessness may be persistent in other areas.

Even, and perhaps especially, if the principal concern is the health of the national economy, a narrow focus on only broad macroeconomic indicators will limit policy makers' understanding of the potential sources of economic growth or stagnation. If a national economy is effectively an aggregation of its regional parts, a subnational view will inevitably be more revealing in its detail than the aggregate perspective in identifying sources of both strength and weakness in an economy.

Given this importance of regional growth, both in itself as well as in its role of clarifying national economic performance, this article analyzes the broad variation of regional economies within 26 countries relative to the Organization for Economic Cooperation and Development (OECD) norm between 1998 and 2003. The primary goal of the analysis is to better understand the role of regions in national growth, while also providing a simple decomposition methodology analogous to shift-share that can assess the relative importance of a range of demographic and economic factors in driving such growth. In particular, this new taxonomy isolates those growth factors involving regionspecific assets that are potentially most influenced by policy. The lessons provided by the broad cross-national comparison should be useful both for regional and national decision makers, as the findings help highlight policy niches that can most effectively shape regional growth prospects while also challenging several conventional wisdoms about regional growth drivers.

\section{WHY REGIONS MATTER}

The process by which regions have become an operational unit of analysis can be linked to evolutions in both the scholarly and policy realms starting in the 1980s, as well as the changing realities of the American economy itself. International economists, with their long mainstream history and well-developed theoretical models, began to apply their frameworks to regional economies, sensing that national boundaries may not be the only demarcations that trace functional economic areas. Paul Krugman's work is perhaps the best-known example, with his 1991 Journal of Political Economy paper often 
considered the fulcrum for much of the ensuing decade's analytical work. The timing of the introduction of these models with Paul Romer's endogenous technical growth vision was fortuitous for regional analysis in that the combination opened a wide range of structures with which to better understand the regional growth process.

Yet such a regional perspective would not be useful at the regional or national level if all regions' economies were behaving similarly, or at least converging towards such homogeneity. In such a case, broad national metrics would be sufficient to understand and analyze broadly similar economic landscapes across an entire nation. However, contemporaneous advances in the empirical field in fact were underscoring the sizable differences in economic performance by region and metro area. Long-standing interest by macroeconomists in convergence between national economies turned to regional economic convergence beginning in the early 1990s with the Barro and Sala-i-Martin (1991) seminal paper. Initial indications suggested that regional convergence was occurring, albeit at a very slow and often conditional pace, but more recent evidence indicates that these trends may often be illusory (e.g., Cheshire and Carbonaro 1995). Similarly, local labor market analysis indicated that many interregional wage and unemployment differentials could persist due to underlying structural factors (e.g., Weiler 2001).

In terms of policy realities, regions are often predefined by the administrative boundaries of locality, county, and state entities, all of which have played an accelerating role in the overall policy process. In the U.S., the 1980s heralded the era of "New Federalism" in which considerable numbers of previously federal programs were devolved to the local and state levels. In general, much of the motivation was to move decisions down to the level of government that had the best knowledge of local contexts. In itself, this devolution necessarily created a subnational "regional" perspective on the provision of public goods and other government services, yet also required a similarly clear perspective on the underlying constraints and opportunities of such regional economies. The policy community thus began to tap into the regional economics expertise that had quietly been developing since the 1950s (Boyce, 2004).

Perhaps most importantly, the increased analytical focus on regions allows a better understanding of overall national economic performance. Both success and stagnation tend to be regionally concentrated in national economies. Therefore, breaking down a region's growth into its core components can offer insights and indicators, respectively, of areas, industries, and policies that are significantly influencing national economic performance. Regions with significantly stronger economies and/or economic components can provide lessons and help lead more lagging regions. In turn, lagging regions and/or components indicate that policy attention might be usefully focused on understanding and helping such areas overcome their challenges. This regional perspective on the macroeconomy has been underutilized in the past, but current research is increasingly highlighting the critical role regions play in fostering a dynamic national economy that can help lift all boats. 


\section{THE SOURCES OF REGIONAL GROWTH}

Growth performances vary significantly among OECD regions. Between 1998 and 2003, the annual growth rate of real GDP ranged between almost 10.2 percent (Newfoundland, Canada) to less than -7.8 percent (Konya, Turkey). Understanding why economic performances differ so widely among regions is not an easy task. Growth is the result of a combination of interconnected factors such as geography, size, demographics, specialization, productivity, and physical and human capital, among others. Sometimes these factors reinforce each other; in other cases, their effects go in opposite directions. In order to identify the sources of regional economic growth, therefore, one needs to disentangle the effects of these different factors. In principle, one can identify three set of interconnected factors.

The first set consists of country-specific features and national policies. For instance, growth will tend to be higher in the regions of a country on the high peak of the business cycle than in the regions of a country in recession. Similarly, sound macroeconomic policies will benefit all regions in a country and result in faster regional growth. The second set of factors center around a region's "natural endowment," region-specific features that tend to be constant over a prolonged period of time. The most obvious example is the presence of oil or diamond mines in a region. Similarly, the rural or urban nature of a region will have an impact on its growth prospects. "Regional assets" represent the third set of factors that influence a region's growth prospects--features that can be mobilized by appropriate policies. For instance, low-productivity regions would experience faster growth if regional policies were successful in upgrading labor skills and stimulating innovation.

The distinction between these three sets of factors has important implications. Country-specific features and national policies are beyond the scope for action of regional policy-makers. As such, they cannot be considered a regional source of growth. The same is true for region-specific natural endowments; they are specific to each region, they may have a significant impact on growth, but they have to be considered as a "given" for regional policy. Regional assets, in contrast, can be influenced and shaped by regional policies and as such become the focus of a regional policymakers toolbox in shaping a region's growth prospects.

The theoretical distinction between natural endowment and regional assets can blur in practice. For instance, industry specialization depends on both natural endowments and regional assets. In fact, the same endowment-landscape-can support a different specialization-agriculture or tourism—depending on the policies that have been carried out, such as promoting transport infrastructure for merchandise or tourism facilities. Similarly, population aging, which is a result of natural demographic trends (i.e., a negative "natural" endowment) can be attenuated or reversed by young migration (i.e., a potential asset). This, in turn, can be stimulated by policies to increase the attractiveness of the region. 
This brief discussion suggests that it is opportune to distinguish these three different sets of growth factors (national, endowments, and assets). In the next section, we present a methodology to measure the contribution of these three different sets to growth.

\section{METHODOLOGY}

Growth performance varies significantly among OECD regions. But why are some regions more competitive than others? Regional benchmarking makes it possible to identify the factors behind the success of certain regions and to perceive the existence of unused resources in others. Regional benchmarking means comparing a region's growth rate to that of all other OECD regions. Successful regions grow faster than others and therefore raise their share of total GDP. GDP growth will be slower in less competitive regions and their share of total OECD GDP will decline.

This section sketches a new methodology to decompose such growth-similar in spirit to a shift-share analysis-into its demographic, economic, and structural components. While the method shares weaknesses with shift-share (e.g., decomposition rather than structural/causal analysis, potential sensitivity to chosen time period, etc.), it nevertheless provides a simple, intuitive, and remarkably revealing perspective on the factors and potential policies that influence regional growth.

\subsection{National and Regional Sources of Growth}

Growth in regional GDP can be regarded as the joint result of several factors. First, regional performance is significantly affected by country-specific factors such as national policies and the business cycle. Second, it depends on region-specific factors stemming from both natural endowments and regional assets. Yet the effectiveness of the latter in bolstering regional growth depends further on regional policies, i.e., on the region's ability to increase productivity, change industry specialization to seize new market opportunities, increase the efficiency of the local labor market, and invest in skills and in innovation. In order to account for the contribution of these different factors, changes in each region's share of GDP in total OECD GDP can be broken down into these.

- National factors: Changes in the country's share of total OECD GDP

- Regional factors: Changes in the region's share of the country's GDP

If all of a country's regions grow faster than the regions in other OECD countries, this faster growth can be ascribed to that country's good performance (national factors). If a region grows faster than all other OECD regions, including those in the same country, faster growth can be ascribed to the region's good performance (regional factors).

\subsection{Seven Key Drivers of Growth}

Regional factors in turn are the result of seven major components. 
- average productivity

- industry specialization

- change in specialization

- employment rates

- participation rates

- age activity rates

- population

Each of these components can be viewed as an indicator of the determinants of economic performance at the regional level. Average productivity is a proxy for the level of productivity across all sectors; industry specialization and changes in specialization capture the contribution of high value-added industries; employment rates measure the efficiency of the local labor market; participation rates summarize the characteristics of the regional labor force; age activity rates and population control for region-specific developments in working age and overall demographic growth. Figure 1 illustrates the methodology to measure the contribution of these seven factors with the help of an example. A detailed derivation of the growth-decomposition methodology is provided in the Appendix.

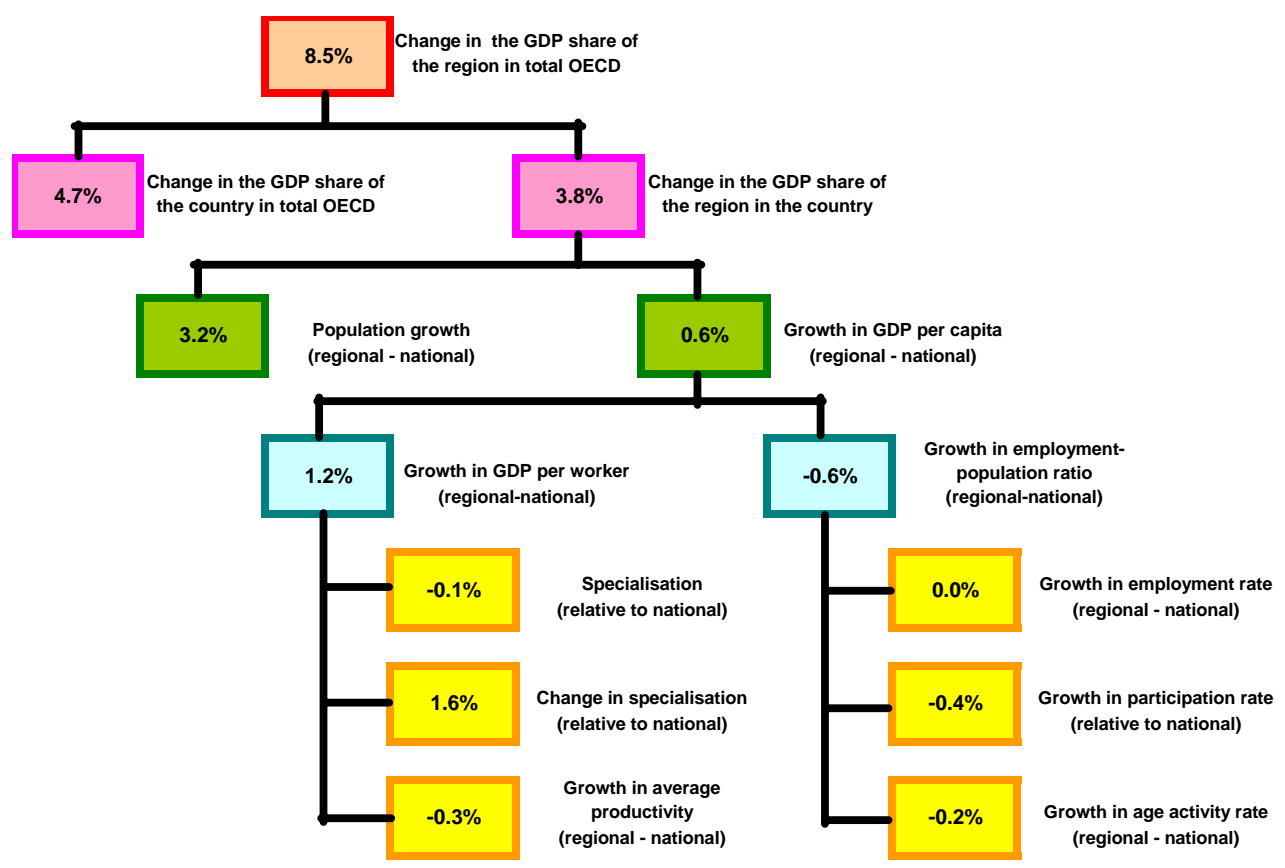

FIGURE 1. The Sources of Economic Growth in an OECD Region 


\subsection{Natural Resources and Regional Assets}

These seven components are affected by two types of resources: natural endowments and regional assets. Natural endowments are the characteristics of a region that cannot be changed or can only be changed in the long run, such as geographic location, natural resources, urban or rural setting, and demographics. Regional assets indicate all the resources that could be more efficiently used and allocated so as to generate a higher level of GDP per capita, such as transport, general infrastructure, tourism-oriented facilities, labor market conditions, and human and social capital. The distinction has important implications for policy. While a region's natural endowments are a "given," regional assets can be mobilized through appropriate policies.

\subsection{Average Productivity}

Changes in a region's share of the country's GDP can be explained in terms of the methodology illustrated in Table 1. A rise in the regional share of GDP may be due to rapid growth - relative to the country's growth rate-in average productivity. Average productivity, in turn, depends on technology, labor skills, production capital and infrastructure. All of these factors can be mobilized through regional policies so as to deliver better productivity through infrastructural investment, higher skill levels (via education and training), and more efficient production technology (via research and innovation). Therefore, the proportion of regional growth that is due to growth in average productivity can be regarded as a result of regional assets.

TABLE 1

The Sources of Regional Economic Growth

\begin{tabular}{|c|c|c|}
\hline $\begin{array}{l}\text { Changes in the regional share of } \\
\text { GDP are due to changes in: }\end{array}$ & Natural Endowments & Regional Assets \\
\hline Average productivity & & $\begin{array}{c}\text { Technology, skills } \\
+ \\
\text { Infrastructure } \\
\end{array}$ \\
\hline Industry specialization & $\begin{array}{l}\text { Irreproducible inputs } \\
\text { (natural resources) }\end{array}$ & $\begin{array}{c}\text { Reproducible inputs } \\
\text { (skills, capital) }\end{array}$ \\
\hline Employment rate & & $\begin{array}{c}\text { Skills of the labor force } \\
+ \\
\text { Labor market efficiency }\end{array}$ \\
\hline Participation rate & & Labor market participation \\
\hline Age activity rate & Ageing & Youth migration \\
\hline Population & Demographics & Migration \\
\hline
\end{tabular}




\subsection{Industry Specialization}

A rise in a region's GDP share may also be due to specialization-in sectors with fast growth of GDP per worker-or to a change in specialization-towards sectors with high GDP per worker. Specialization is a result of a region's comparative advantages, which depend on both irreproducible (e.g., land, oil) and reproducible (e.g., skills, capital) inputs. The proportion of regional GDP growth due to specialization based on irreproducible inputs can attributed to natural endowments. However, unlike the stock of irreproducible inputs that is fixed, skills can be upgraded through education and training, capital can be accumulated through investments. Therefore, the proportion of regional growth due to specialization based on reproducible inputs can be regarded as a function of regional assets.

\subsection{The Labor Market and Population}

High growth in employment rates may be due to higher skill levels—skilled workers have higher employment rates than unskilled ones-or to greater efficiency of the local labor market - regulations and institutions providing a better match between labor supply and demand. Both can be regarded as resulting from regional assets. Skills can be upgraded through training and education, and changes in employment regulations and labor institutions can increase the efficiency of the regional labor market.

A relative rise in activity rates may be the result of an increase in the working-age population or of an increase in participation rates across all age groups. Higher rates of growth of the working-age population may follow natural demographic trends or may be due to policies to attract working-age migrants from other regions and countries. Therefore, a rise in activity rates due to natural demographic trends can be seen as resulting from natural endowments. In contrast, an increase in the working-age population via migration and higher participation rates across all age groups is an indicator of regional assets. Finally, higher rates of population growth may follow natural demographic trends or may be due to policies to attract migrants from other regions and countries.

\section{THE SOURCES OF REGIONAL GROWTH: MAIN FINDINGS}

Given the noted taxonomy and decomposition method, we can now identify major patterns in the sources of economic growth in OECD regions over the period 1998-2003. In any analytical study conducted at the subnational level, the choice of the territorial unit is of prime importance. The word "region" can mean very different things both within and between countries. To address this issue, the OECD has classified regions within each member country in two Territorial Levels (TLs). The higher level (Territorial Level 2) consists of 335 macro-regions (e.g., consisting of 50 states in the U.S.), while the lower level (Territorial Level 3) is composed of 1,679 micro-regions (e.g., consisting of 179 groups of counties in the U.S.). This classification facilitates greater comparability of regions at the same territorial level. Indeed, these two levels, which are officially 
established and relatively stable in all member countries, are used by many as a framework for implementing regional policies.

Data is drawn from the OECD Regional Database and covers 297 TL2 regions, the whole territory of 26 OECD countries. Iceland, New Zealand, and Switzerland are not considered because regional GDP is not available in these countries; Luxembourg consists of one region only. By OECD convention, the name of the region is presented in the national language.

In several respects, five years is a short period to assess the factors of growth of regions. Some of the observed patterns are likely to be cyclical. Therefore, it is difficult to determine whether they would persist in the long run. However, all regions are considered at identical beginning and ending points, facilitating comparisons across regions during this particular world economic cycle. The choice of this period for the analysis is mainly driven by data availability: unfortunately, 1998-2003 is the most recent and the longest period for which data are available for a large number of OECD regions.

Figure 2 shows the proportional changes in the regional shares in the total GDP of the OECD over 1998-2003, according to the initial share in 1998. The largest changes occurred in regions with a small share of the total GDP of the OECD. Faster growth, above 10 percent, occurred almost exclusively in regions with a share below 0.5 percent. Similarly, regions in the same size class showed the largest decrease in their share, below -10 percent. Variations in the share of medium-size regions (between 0.5 and 2.5 percent) remained within the range of 10 percent, either above or below their 1998 share. Seoul was the only region in this size class (1.2 percent) to show a much higher growth rate of its share (23 percent). Among large-size regions (above 2.5 percent), the shares of Texas (2.7 percent in 1998) and California (4.6 percent) increased, respectively, by 4.9 percent and 6.0 percent, while the shares of New York State (2.9 percent) and Kanto (5.3 percent) decreased by -2.0 percent and -5.6 percent, respectively.

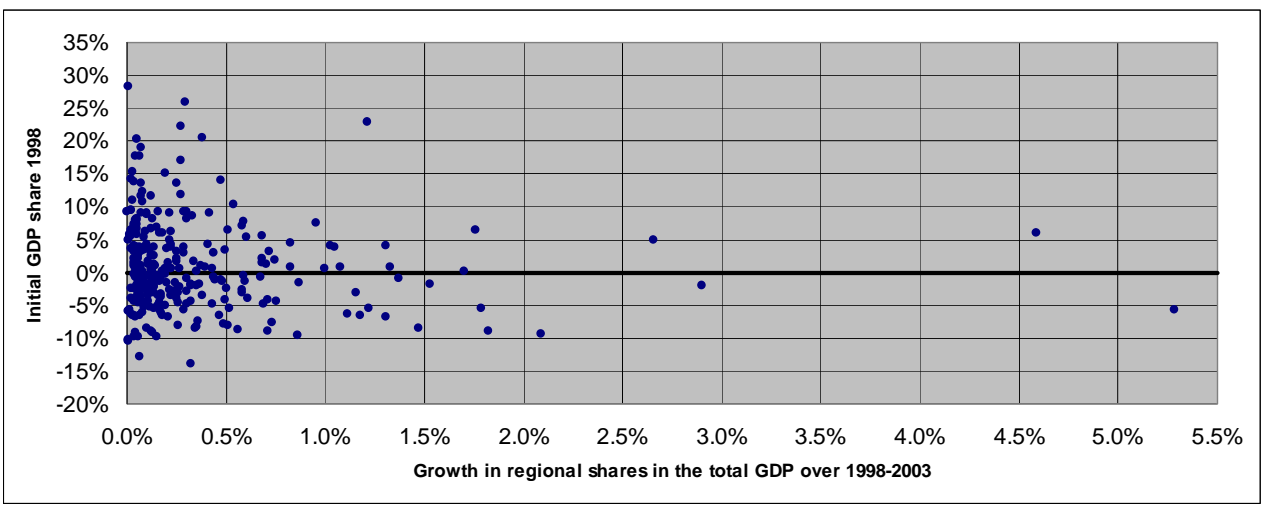

FIGURE 2. Changes in GDP Share and Initial Share of GDP 


\subsection{Fast-Growing Regions}

Over 1998-2003, 149 regions out of 297 increased their share in the OECD's total GDP. The top 20 fast-growing regions (Figure 3) were as follows.

- Canada: Northwest Territories (ranking 1) and Alberta (5)

- Ireland: Southern and Eastern (2) and Border, Midlands, and Western (7)

- Korea: Seoul region (3), Chungcheong region (4), Gyeonbuk region (10), Jeju (11), Gyeongnam region (14) and Gangwon region (18)

- Czech Republic: Stredni Cechy (6)

- Mexico: Quintana Roo (8) and Campeche (15)

- U.S.: Wyoming (9) and Nevada (19)

- Hungary: Kosep-Magyarorszag (12)

- Australia: Northern Territories (13)

- Spain: Murcia (16) and Canaries (20)

- Greece: Athens region (17)

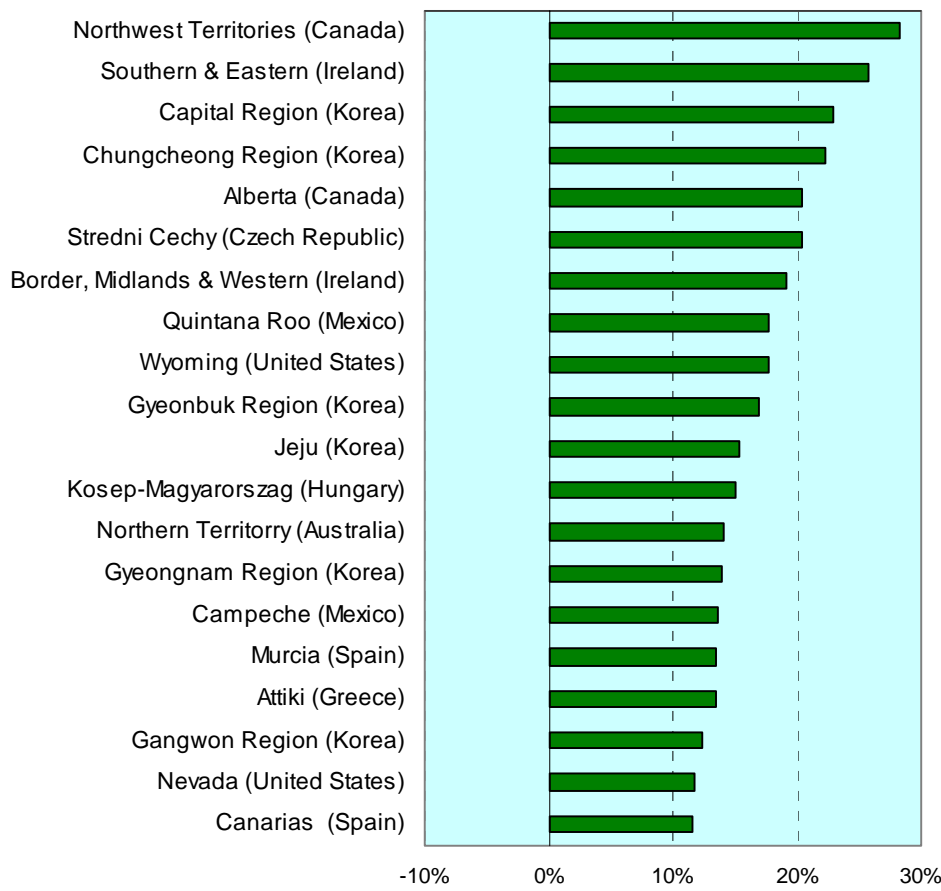

Change in the regional GDP share of the OECD (1998-2003)

FIGURE 3. Increase in the GDP Share of the 20 Fastest-Growing OECD Regions 
In about 60 percent of the 149 regions that increased their share, regional factors explain more than 25 percent of the increase in their share of the OECD total GDP, the remainder being due to national factors. In most cases, therefore, the good international performances of regions were driven by their own success rather than the success of their country. In fact, a significant number of regions (23) increased their GDP share in the OECD despite the weak performances of their countries (Table 2). The region of Algarve, for instance, increased its share in the OECD by about 11 percent although Portugal's share decreased by 2.5 percent. Similarly, the decrease in Austria's OECD share (-2.6 percent) did not prevent the region of Burgenland from increasing its OECD share by 3.6 percent.

A similar pattern-increase in the regional GDP share despite a decrease in the national one-was also observable in some regions in France (Languedoc-Roussillon, Provence-Alpes-Côte d'Azur, Midi-Pyrénées, Pays de la Loire, Bretagne, PoitouCharentes, Limousin and Ile de France), Italy (Friuli-V. Giulia and Bolzano), and Norway (Hedmark og Oppland, Trøndelag and Oslo) as well as in other regions in Austria (Vorarlberg and Tirol) and Portugal (Madeira and Açores). Regional effects were also very strong (above 90 percent) in Stredni Cechy (Czech Republic), Wyoming and Nevada (U.S.), and in most of the fast-growing Mexican states (Quintana Roo, Campeche, Baja California Sur, Tamaulipas, Yucatan, Aguacalientes, Nuevo Leon, Oaxaca, Tlaxcala and Tabasco).

For the whole group of 88 regions where regional factors had significant impact (i.e., above 25 percent), the increase in the OECD share was due to a relative increase in population in 19 percent (or 17) of regions, a relative increase in GDP per capita in 36 percent (or 32), and a relative increase in both components in the remaining 44 percent (or 39). The highest population growth occurred in Quintana Roo (18.1 percent), Nevada (13.8 percent), and Baja California Sur (10.1 percent) while the regions with the highest GDP per capita growth were Northwest Territories (21 percent), Wyoming (19.7 percent), and Stredni Cechy (16.9 percent). A majority of fast-growing regions (44 percent or 39 regions) were successful not only in increasing population but also in increasing GDP per inhabitant.

On average, the increase in the regional GDP share-controlling for national effects - was the largest for those regions that managed to increase both their population and their level of GDP per capita (6.4 percent). Nonetheless, the increase in GDP share due to population growth alone (4.4 percent) was larger than the increase due to growth in GDP per capita alone (4.3 percent). Population growth, therefore, was the only source of growth in about 20 percent (or 17) of the fast-growing regions. In addition, the rate of growth due to population growth was above the rate due to growth in GDP per capita only. 
Spiezia/Weiler: Understanding Regional Growth

TABLE 2

\begin{tabular}{|c|c|c|c|c|}
\hline \multicolumn{2}{|c|}{ Country } & \multirow{2}{*}{$\begin{array}{l}\text { Regions } \\
\text { Algarve }\end{array}$} & \multirow{2}{*}{$\begin{array}{c}\begin{array}{c}\text { Change in GDP } \\
\text { Share of Regions in } \\
\text { OECD }(\%)\end{array} \\
10.9\end{array}$} & \multirow{2}{*}{$\begin{array}{c}\text { Change in GDP } \\
\text { Share of Country } \\
\text { in OECD (\%) } \\
-2.5\end{array}$} \\
\hline 1 & Portugal & & & \\
\hline 2 & Portugal & Madeira & 9.4 & -2.5 \\
\hline 3 & France & Corse & 6.4 & -0.8 \\
\hline 4 & France & Landguedoc - & & \\
\hline & & Roussillon & 5.9 & -0.8 \\
\hline 5 & Portugal & Açores & 5.8 & -2.5 \\
\hline 6 & France & $\begin{array}{l}\text { Provence-Alpes-Côte } \\
\text { d'Azur }\end{array}$ & 4.3 & -0.8 \\
\hline 7 & France & Midi-Pyrénées & 3.9 & -0.8 \\
\hline 8 & France & Pays de la Loire & 3.9 & -0.8 \\
\hline 9 & Austria & Burgenland & 3.6 & -2.6 \\
\hline 10 & Austria & Vorarlberg & 2.1 & -2.6 \\
\hline 11 & France & Bretagne & 1.6 & -0.8 \\
\hline 12 & France & Poitou-Charentes & 1.3 & -0.8 \\
\hline 13 & Austria & Tirol & 0.9 & -2.6 \\
\hline 14 & Norway & Hedmark og Oppland & 0.9 & -2.1 \\
\hline 15 & France & Limousin & 0.8 & -0.8 \\
\hline 16 & Belgium & Brussels & 0.7 & -1.6 \\
\hline 17 & Norway & Trøndelag & 0.7 & -2.1 \\
\hline 18 & France & Aquitaine & 0.6 & -0.8 \\
\hline 19 & Norway & Oslo og Akershus & 0.3 & -2.1 \\
\hline 20 & Italy & Bolzano & 0.2 & -4.3 \\
\hline 21 & Netherlands & Zuid-Nederland & 0.2 & -1.1 \\
\hline 22 & Italy & Friuli-V. Giulia & 0.1 & -4.3 \\
\hline 23 & France & Ile de France & 0.1 & -0.8 \\
\hline
\end{tabular}

Among the 71 regions that increased their GDP per capita relative to their countries, 42 percent (or 30 regions) did so by increasing GDP per worker only, 21 percent (or 15 regions) by increasing the employment-population ratio, and the remaining 37 percent (or 26 regions) by increasing both components. The employment-population ratio grew most in Limousin (18.1 percent), Pays de la Loire (17.5 percent), and Campeche (16.2 percent); the highest growth in GDP per worker occurred in Course (37.5 percent), Northwestern Territories (19.6 percent), and Northern Territory and Stredni Cechy (14 percent). On average, the increase in the regional GDP share-controlling for national effects-was the largest for those regions that increased both their employmentpopulation ratio and their level of GDP per worker (8.0 percent). Nonetheless, the increase in GDP share due to growth in the employment-population ratio alone (4.3 percent) was larger than the increase due to growth in GDP per worker alone (3.9 percent). In a majority of the fast-growing regions of the OECD (58 percent or 41 regions), the increase in GDP per capita was driven by improved performances in their labor market, either alone or in combination with an improvement in production. In 
addition, the rate of growth due to growth in the employment-population ratio was above the rate due to growth in GDP per worker only. Therefore, the performance of the regional labor market is an important factor in shaping positive regional growth prospects.

Among the 41 regions that increased their employment-population ratio relative to their countries, there were none where this increase was entirely due to an increase in the age activity rate. Acores (3.8 percent) and Rhode Island (3.0 percent) were the only two regions where the relative increase in young population had a noticeable effect on the growth of their OECD GDP shares (3.8 percent and 3.0 percent, respectively). There were 15 percent (or 6) regions that only increased their rate of employment, and 29 percent (12 regions) with an increased only in the rate of participation. The remaining 56 percent (or 23) increased both the rate of employment and the rate of participation. The employment rate grew the most in Northwest Territories (4.4 percent), LangeudocRoussilon (3.8 percent), and Montana (2.8 percent). The rate of participation experienced the largest growth in Limousin (19.6 percent), Pays de la Loire (16.2 percent), and Campeche (14.4 percent). Therefore, growth in the participation rate was the most important labor market component promoting growth in the employment-population ratio.

Among the 55 fast-growing regions that increased their GDP per worker relative to their countries, 51 percent (or 28 regions) did so by increasing average labor productivity only, 13 percent (or 7 regions) through industry specialization, and the remaining 36 percent (or 20 regions) by improving both components. The largest impact of specialization on GDP growth was recorded in Distrito Federal (7.6 percent), Bolzano (6.8 percent), and Nova Scotia (6.5 percent). Change in relative specialization was the largest in Burgenland (4.2 percent), Taumaulipas (3.1 percent), and Wyoming (1.9 percent). Finally, growth in average productivity was the highest in Guerrero (20.4 percent) and Northern Territory (19.2 percent). On average, the increase in GDP share-controlling for national effects-was larger for those regions that increased average productivity, either alone (5.6 percent) or in combination with specialization (6.0 percent), than for regions where GDP growth was only due to specialization (3.7 percent). Therefore, growth in average productivity was the largest single source of regional growth.

Table 3 displays the contribution of each factor to changes in the GDP share of the region in the country for fast-growing regions. Population and growth in average productivity were the largest sources of regional growth after controlling for national factors. 
TABLE 3

\begin{tabular}{lc}
\multicolumn{2}{c}{ Contribution of Factors to Fast-Growing Regions } \\
\hline & Contribution to Change in the GDP \\
Factors of Growth & Share of the Region in the Country (\%) \\
\hline Population & 19 \\
Productivity & 17 \\
Specialization & 4 \\
Productivity and Specialization & 12 \\
Employment rate & 3 \\
Participation rate & 5 \\
Employment and Participation rate & 10 \\
All Factors & 30 \\
\hline Total & 100 \\
\hline
\end{tabular}

\subsection{Slow-Growing Regions}

Over 1998-2003, 148 regions out of 297 decreased their shares in the total OECD GDP. The 20 worst-performing regions (Figure 4) were as follows.

- Germany: Berlin (ranking 1), Nordrhein-Westfalen (12), MecklenburgVorpommern (13), Niedersachsen (14), and Saarland (18)

- Czech Republic: Moravskoslezko (2)

- Spain: Cuidad Autónoma de Melilla (3) and Cuidad Autónoma de Celta (4)

- Poland: Opolskie (5)

- Norway: Nord-Norge (6)

- France: Bourgogne (7) and Champagne-Ardenne (10)

- Japan: Tohoku (8), Kinki (9), Hokuriku (15), Shikoku (19), Hokkaido (20)

- Italy: Basilicata (11)

- Mexico: Mexico (16)

- United States: Ohio (17)

In about 68 percent (102) of the 148 regions that decreased their shares, regional factors explain more than 25 percent of the decrease (the remainder being due to national factors); and in about 40 percent (60 out of 148), the regional effects were above 90 percent. A significant number of regions (69) decreased their GDP share in the OECD despite the strong performance of their countries. Table 4 list the 20 regions (out of the 69) that declined the most. The region of Moravskoslezko, for instance, decreased its share in the OECD by about -13 percent, although the share of the Czech Republic in the OECD increased by 0.4 percent. Similarly the national increase in Spain's OECD share (6.9 percent) did not trigger an increase in the shares of Melilla (-10.4 percent) or Ceuta (-10.2 percent). Therefore, in most cases, weak international performances of regions were driven by their own poor performance rather than the poor performance of their countries. 


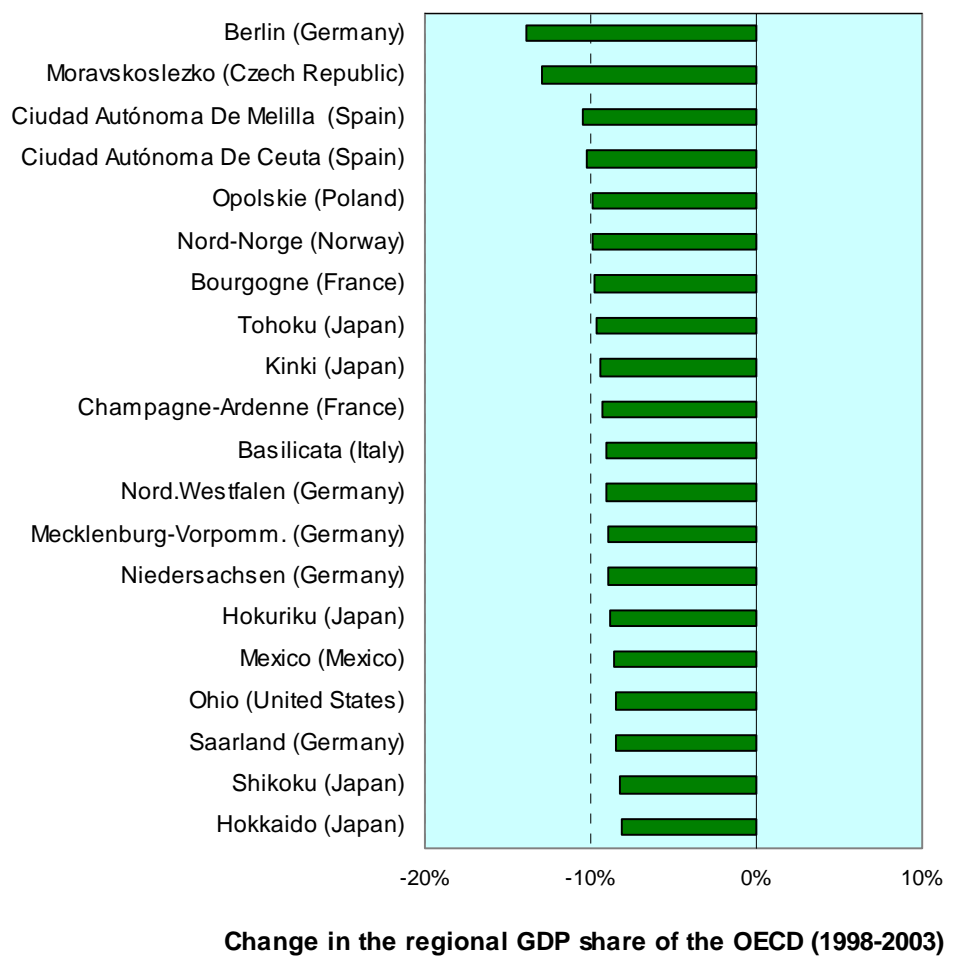

FIGURE 4. Decrease in the GDP Share of the 20 Slowest-Growing OECD Regions

For the whole group of 102 regions where regional factors had significant impact (i.e., above 25 percent), the decline in the OECD share was due to a relative decrease in population in 17 percent (or 17) of regions, a relative decrease in GDP per capita in 21 percent (or 21), and a relative decrease in both components in the remaining 63 percent (or 64). The lowest population growth was recorded in Del-Alfold (-7.5 percent), Nayarit (-6.5 percent), and Michigan (-6.1 percent). The lowest GDP per capita growth occurred in Kinki (-13.9 percent), Steiermark (-12.3 percent), and Tohoku (-12.2 percent). Therefore, a majority of slow-growing regions (63 percent or 64 regions) were unsuccessful not only in increasing population but also in increasing GDP per inhabitant.

On average, the decrease in the regional GDP share-controlling for national effects -was the largest for those regions that decreased both their population and their level of GDP per capita (-5.6 percent). Nonetheless, the decrease in GDP share due to GDP per capita alone (-3.9 percent) was larger than the decrease due population growth (-2.0 percent) alone. GDP per capita growth, therefore, was the only source of growth in about 21 percent of slow-growing regions. In addition, the rate of growth due to GDP per capita was below the rate of growth due to population growth. 
Spiezia/Weiler: Understanding Regional Growth

TABLE 4

\begin{tabular}{rllcc}
\multicolumn{5}{c}{ Regions Decreasing GDP Shares in the OECD Despite Strong Country Performance } \\
\hline & \multicolumn{1}{c}{ Country } & \multicolumn{1}{c}{ Regions } & Change in GDP Share in OECD (\%) \\
\cline { 3 - 5 } & & Regions & Country \\
\hline 1 & Czech Republic & Moravskoslezko & -12.9 & 0.4 \\
2 & Spain & Cdad. Aut. de Melilla & -10.4 & 6.9 \\
3 & Spain & Cdad. Aut de Ceuta & -10.2 & 6.9 \\
4 & Poland & Opolskie & -9.9 & 2.9 \\
5 & Mexico & Mexico & -8.5 & 0.3 \\
6 & United States & Ohio & -8.5 & 1.0 \\
7 & United States & Michigan & -6.8 & 1.0 \\
8 & Mexico & Hidalgo & -6.7 & 0.3 \\
9 & Mexico & Zacatecas & -6.6 & 0.3 \\
10 & Sweden & Mellesta-Norrland & -6.6 & 1.5 \\
11 & United States & Kentucky & -6.6 & 1.0 \\
12 & Mexico & Michoacan & -6.2 & 0.3 \\
13 & Canada & Yukon & -5.9 & 5.1 \\
14 & United States & West Virginia & -5.7 & 1.0 \\
15 & United States & Illinois & -5.5 & 1.0 \\
16 & United States & Oregon & -4.9 & 1.0 \\
17 & Mexico & Sonora & -4.9 & 0.3 \\
18 & United States & Missouri & -4.8 & 1.0 \\
19 & United States & Mississippi & -4.5 & 1.0 \\
20 & Mexico & Coahuila & -4.5 & 0.3
\end{tabular}

Among the 85 regions that decreased their GDP per capita relative to their countries, 46 percent (or 39 regions) did so by decreasing GDP per worker, only 20 percent (or 17 regions) by decreasing the employment-population ratio, and the remaining 34 percent (or 29 regions) by decreasing both components. The employment-population ratio grew the least in Scotland (-11.4 percent), West-Nederland (-11.3 percent), and Piemonte (-8.9 percent), while GDP per worker decreased the most in Wisconsin (-24.4 percent), Queretaro (-17 percent), and Nordrhein-Westfalen (-16.7 percent). On average, the decrease in regional GDP share-controlling for national effects-was largest for those regions that decreased both their employment-population ratio and their level of GDP per worker (-6.1 percent). Nonetheless, the decrease in GDP share due to a decline in growth GDP per worker alone ( -4.9 percent) was larger than a decrease due to a decline in growth in the employment-population ratio (-4.2 percent). Therefore, in the majority of slow-growing regions of the OECD (80 percent or 68 out of 85), the decrease in GDP per capita was driven by a decrease in labor productivity, either alone or in combination with weakness in the labor market. In addition, the rate of growth due to labor productivity was below the rate due to the employment-population ratio alone. Therefore, weak labor productivity is an important factor explaining poor growth in stagnating regions.

Among the 44 regions that decreased their employment-population ratio relative to their countries, there were none where this decrease was entirely due to a decrease in the 
age activity rate. Thirty-nine percent of regions (or 17 regions) did so by decreasing participation rates only, 18 percent (or 8 regions) by decreasing their employment rate only, and the remaining 43 percent (or 19 regions) decreased both their participation and their employment rates. The employment rate grew the least in Piemonte (-3.7 percent), Steiermark (-3.5 percent), and Niedersachsen (-3.0 percent). The participation rate grew the least in West-Nederland (-23.6 percent), Kinki (-15.6 percent), and Hidalgo (-11.9 percent); the lowest growth in the age activity rate was recorded in Haute-Normandie, Stredni Morava (-1.6 percent), and Michoacan (-1.3 percent). Therefore, a decreasing participation rate was the most important labor market component affecting the stagnant growth in regional employment-population ratios.

Among the 85 regions that decreased their GDP per capita, 64 of them (or 75 percent) also decreased their GDP per worker relative to their countries. Among these 64 regions, 33 percent (or 21 regions) did so by decreasing average productivity only, 9 percent (or 6 regions) by decreasing industry specialization only, and the remaining 58 percent (or 37 regions) by decreasing both components. The lowest increase in industry specialization was recorded in Baja California Norte ( -4.7 percent), Mellersta Norland (-4.6 percent), and Alabama (-3.3 percent). The lowest growth in average productivity occurred in Wisconsin (-24.2), Queretaro (-16.8 percent), and Nordrhein-Westfalen (-16.3 percent). Therefore, the decline in growth in average productivity was the most important component explaining declining growth in GDP per worker.

Table 5 displays the contribution of each factor to changes in the GDP share of regions in the country for slow-growing regions. A decline in average productivity (either alone or in conjunction with specialization) and a decline in population were the largest sources that reduced regional growth after controlling for national factors.

TABLE 5

Contribution of Factors to Slow-Growing Regions

\begin{tabular}{lc}
\hline Factors of Growth & $\begin{array}{c}\text { Contribution to Change in GDP Share of } \\
\text { Regions in the Country (\%) }\end{array}$ \\
\hline Population & 17 \\
Productivity & 12 \\
Specialization & 4 \\
Productivity and Specialization & 21 \\
Employment rate & 3 \\
Participation rate & 6 \\
Employment and Participation rate & 7 \\
All Factors & 28 \\
\hline Total & 100 \\
\hline
\end{tabular}


Spiezia/Weiler: Understanding Regional Growth

\section{FOSTERING REGIONAL GROWTH: CHALLENGING CONVENTIONAL WISDOMS}

Although the results are limited to a short time period, they do allow for some instructive comparisons with some of the common "conventional wisdoms" about the drivers of regional growth. The first widely-held belief is that fast-growing regions are those with a rapid growth in productivity. This belief is seemingly confirmed (Table 3) by the finding that in a large number (29 percent) of regions, fast growth in GDP was due to faster growth in productivity, either alone (17 percent) or in conjunction with specialization (12 percent). Nonetheless, a significant number of regions owe their good performance to factors other than productivity growth: 5 percent due to the participation rate alone, 3 percent to the employment rate, 10 percent to both the participation and the employment rate, and 19 percent to growth in population. In 30 percent of regions, fast growth of GDP was due to a combination of all four factors (i.e., participation rate, employment rate, productivity, and specialization).

Even more interestingly, after controlling for national factors, the average increase in regional GDP share due to average productivity alone (5.6 percent) or due to both average productivity and specialization (6.0 percent) was below the average increase due to the employment rate alone (11.1 percent) or due both to employment rate and participation rate (6.8 percent). Therefore, although productivity is an important factor of growth, regions have a larger set of potential assets that can be used to enhance growth.

A second common belief is that there is a trade-off between productivity and employment. Higher productivity means higher competitiveness and faster growth, but it also means fewer workers per unit of output produced and potentially less employment. By contrast, an increase in employment could mean that workers with lower skills enter production so that productivity decreases. According to this view, regions have to choose between fast productivity growth and slow employment growth or slow productivity growth and fast employment growth. Although the findings of this report find some evidence for this trade-off, they also show that productivity versus employment is not an unavoidable choice by any means. Among the 71 regions that grew in GDP per capita, 46 percent (33) were able to increase the rate of employment and the level of average productivity simultaneously. Furthermore, the average increase in the share in the total GDP of the OECD was significantly higher for these 33 regions (7.9 percent) than for the remaining 38 (4.7 percent). Therefore, a significant number of regions were successful in increasing productivity and employment at the same time. Note also that for fast-growing regions, the rate of growth due to population growth was more important than growth due to GDP per capita only. In contrast, for slow-growing regions the decline in growth due to GDP per capita was more important than population growth.

Finally, a third common belief is that labor market participation is largely determined by labor demand. Higher employment rates mean greater opportunities for job-seekers and stronger incentives to enter the labor market. Therefore, one would expect that increases in participation rates occurred almost exclusively in regions showing an 
increase in employment rates. Although the findings of this report find some evidence for this positive link, they also show that evolutions in labor supply are by no means simply responding to shifts in labor demand. Among the 41 regions that increased the employment-population ratio, more than half (56 percent or 23 regions) increased the participation rate and employment rate simultaneously, indicating that the growth of employment had a positive effect on the rate of labor participation in that region. However, among the remaining 44 percent (18) of regions, 29 percent (12) were successful in increasing participation rates despite a decrease in employment rates; while in 15 percent (6) the increase employment rates did not seem to provide any effect on labor market participation. Therefore, both labor supply and labor demand seem to matter to foster regional growth.

The novel methods and OECD results of the study allow new insights into the key sources of both regional and national growth. In particular, they point out the major factors underlying the economic performances of each region, which in turn can help inform policymakers about regions, industries, and structures that are driving regional and macroeconomic growth patterns. Although these results cannot be directly translated into policy recommendations, they nevertheless highlight the role of specific policymalleable regional assets in shaping growth prospects while also challenging conventional wisdoms which can obscure potentially promising policy approaches.

\section{REFERENCES}

Barro, R. and X. Sala-i-Martin, 1991. "Convergence Across States and Regions," Brookings Papers on Economic Activity 1, 107-182.

Boyce, D., 2004. “A Short History of the Field of Regional Science,” Papers in Regional Science 83(1-2), 31-58.

Cheshire, P. and G. Carbonaro, 1995. "Convergence and Divergence in Regional Growth Rates: An Empty Black Box?” in H.W. Armstrong and R.W. Vickerman (eds.), Convergence and Divergence among European Regions. Pion: London.

Krugman, P., 1991. Geography and Trade. MIT Press: Cambridge, MA. , 1996. The Self-Organizing Economy. Blackwell: Cambridge, MA.

$\widehat{O E C D}, 2007$. Regions at a Glance. OECD: Paris.

Weiler, S., 2001. "Unemployment in Regional Labor Markets: Using Structural Theories to Understand Local Jobless Rates in West Virginia," Industrial and Labor Relations Review 54(3), 573-592.

\section{APPENDIX: A DECOMPOSITION ANALYSIS OF REGIONAL GROWTH}

The share of region $i$ in the total GDP of the OECD is equal to:

$$
\frac{G D P_{i}}{G D P_{O E C D}}=\frac{G D P_{j}}{G D P_{O E C D}} * \frac{G D P_{i}}{G D P_{j}}
$$


where $j$ denotes the country of region $i$. Equation A1 shows that the GDP share of a region in the OECD depends on the GDP share of its country in the OECD $\left(\mathrm{GDP}_{j} / \mathrm{GDP}_{O E C D}\right)$ and on the region's share in the country $\left(\mathrm{GDP}_{j} / \mathrm{GDP}_{j}\right)$. The GDP share of region $i$ in country $j$ is then equal to:

$$
\frac{G D P_{i}}{G D P_{j}}=\left(\frac{G D P_{i} / P_{i}}{G D P_{j} / P_{j}}\right) * \frac{P_{i}}{P_{j}}
$$

where $P$ denotes population. Equation A2 shows that the GDP share of a region in a country is a function of the region's GDP per capita $\left(G D P_{i} / P_{i}\right)$ and population (Pi) relative to, respectively, the GDP per capita $\left(G D P_{j} / P_{j}\right)$ and the population $\left(P_{j}\right)$ of the country.

The relative GDP per capita of region $i$ is equal to:

$$
\left(\frac{G D P_{i} / P_{i}}{G D P_{j} / P_{j}}\right)=\left(\frac{G D P_{i} / E_{i}}{G D P_{j} / E_{j}}\right) *\left(\frac{E_{i} / P_{i}}{E_{j} / P_{j}}\right)
$$

where $E$ denotes employment. Equation A3 shows that the relative GDP per capita of a region is a function of the region's GDP per worker $\left(G D P_{i} / E_{i}\right)$ and employmentpopulation ratio $\left(E_{i} / P_{i}\right)$ relative to, respectively, the GDP per worker $\left(G D P_{j} / E_{j}\right)$ and the employment-population ratio $\left(E_{j} / P_{j}\right)$ of the country.

The relative employment-population ratio of region $i$ is equal to:

$$
\left(\frac{E_{i} / P_{i}}{E_{j} / P_{j}}\right)=\left(\frac{E_{i} / L F_{i}}{E_{j} / L F_{j}}\right) *\left(\frac{L F_{i} / W A_{i}}{L F_{j} / W A_{j}}\right) *\left(\frac{W A_{i} / P_{i}}{W A_{j} / P_{j}}\right)
$$

where $L F$ and WA stand, respectively, for labor force and working age (15-64) population. Equation A4 shows that the relative employment-population ratio of a region in the country is a function of the region's employment rate $\left(E_{i} / L F_{i}\right)$, participation rate $\left(L F_{i} / W A_{i}\right)$ and age-activity rate $\left(W A_{i} / P_{i}\right)$ relative to, respectively, the employment rate $\left(E_{j} / L F_{j}\right)$, participation rate $\left(L F_{j} / W A_{j}\right)$, and age-activity rate $\left(W A_{j} / P_{j}\right)$ of the country. By substituting Equations A2, A3, and A4 into Equation A1, taking the logarithm and differentiating, one obtains:

(A5) $\left(g_{i}-g_{\text {oecd }}\right)=\left(g_{j}-g_{\text {oecd }}\right)+\left(g_{p w, i}-g_{p w, j}\right)+\left(g_{e, i}-g_{e, j}\right)+\left(g_{I f, i}-g_{I f, j}\right)+\left(g_{w a, i}-g_{w a, j}\right)+\left(g_{p, i}-g_{p, j}\right)$

or, equivalently 


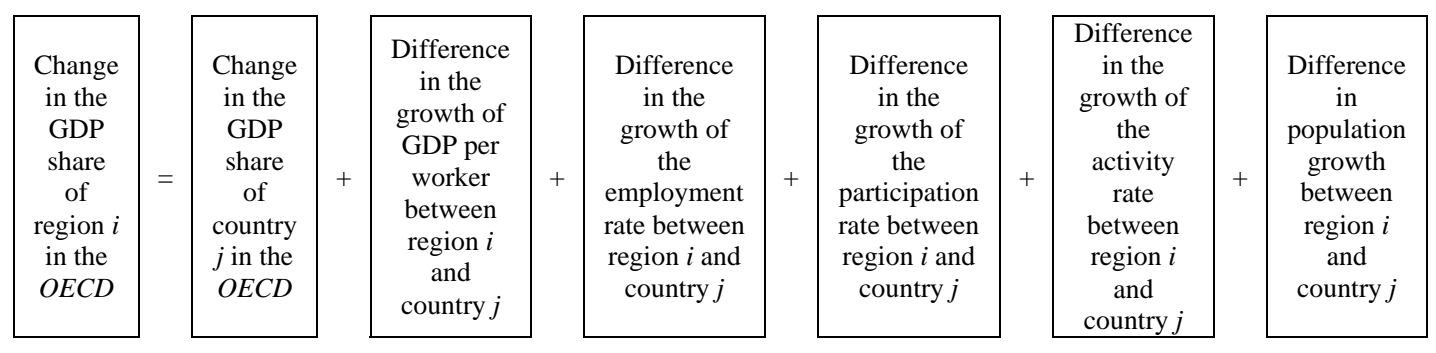

The difference in the growth of GDP per worker can be further decomposed by observing that GDP per worker in region $i$ is equal to a weighted average of sectoral GDP per worker:

$$
\frac{G D P_{i}}{E_{i}}=\sum_{k} \frac{E_{i k}}{E_{i}} * \frac{G D P_{i k}}{E_{i k}}
$$

where $k$ indicates the sector and the weights are given by the employment share of the each sector $\left(E_{k i} / E_{i}\right)$.

By differentiating 6, one obtains:

$$
g_{p w, i}=\sum_{k} \pi_{k i}\left[\frac{E_{k i}}{E_{i}} * g_{p w, k i}+\Delta\left(\frac{E_{k i}}{E_{i}}\right)\right]
$$

where $\pi_{k i}=\left(\frac{G D P_{k i} / E_{k i}}{G D P_{i} / E_{i}}\right)$ denotes GDP per worker in sector $k$ relative to the average GDP per worker of region $i$ and $g_{p w, k i}$ the growth of GDP per worker of sector $k$ in region i.

Equation A7 shows that productivity growth in region $i$ is driven by sectoral productivity growth and by changes in sectoral employment shares. A similar equation defines growth in GDP per worker in country $j$ :

$$
g_{p w, j}=\sum_{k} \pi_{k j}\left[\frac{E_{k j}}{E_{j}} * g_{p w, k j}+\Delta\left(\frac{E_{k j}}{E_{j}}\right)\right]
$$

where $\pi_{k j}=\left(\frac{G D P_{k j} / E_{k j}}{G D P_{j} / E_{j}}\right)$ denotes GDP per worker in sector $k$ relative to the average GDP per worker of country $j$ and $g_{p w, k j}$ the growth of GDP per worker of sector $k$ in country $j$.

Subtracting A8 from A7 and rearranging, one obtains: 


$$
\begin{aligned}
\left(g_{p w, i}-g_{p w, j}\right) & =\sum_{k} \pi_{k j} * g_{p w, k j} *\left(\frac{E_{i k}}{E_{i}}-\frac{E_{j k}}{E_{j}}\right)+\sum_{k} \pi_{k j} *\left[\Delta\left(\frac{E_{i k}}{E_{i}}\right)-\Delta\left(\frac{E_{j k}}{E_{j}}\right)\right] \\
& +\sum_{k}\left(\pi_{k i}-\pi_{k j}\right) *\left[\Delta\left(\frac{E_{k i}}{E_{i}}\right)+\frac{E_{k i}}{E_{i}} * g_{p w, k i}\right] \\
& +\sum_{k} \pi_{k j} * \frac{E_{k i}}{E_{i}} *\left(g_{p w, k i}-g_{p w, k j}\right)
\end{aligned}
$$

\begin{tabular}{|c|c|c|c|c|c|c|c|c|}
\hline $\begin{array}{l}\text { Difference } \\
\text { in } \\
\text { the growth } \\
\text { of GDP per } \\
\text { worker } \\
\text { between } \\
\text { region } i \text { and } \\
\text { country } j\end{array}$ & $=$ & $\begin{array}{l}\text { Regional } \\
\text { specialization } \\
\text { in sectors } \\
\text { with fast } \\
\text { growth in } \\
\text { GDP per } \\
\text { worker }\end{array}$ & + & $\begin{array}{l}\text { Change in } \\
\text { regional } \\
\text { specialization } \\
\text { towards } \\
\text { sectors with } \\
\text { high GDP per } \\
\text { worker }\end{array}$ & + & $\begin{array}{l}\text { Differences in } \\
\text { the relative level } \\
\text { of GDP per } \\
\text { worker between } \\
\text { region } i \text { and } \\
\text { country } j \text { across } \\
\text { all sectors }\end{array}$ & + & $\begin{array}{l}\text { Differences in } \\
\text { the growth of } \\
\text { GDP per } \\
\text { worker } \\
\text { between } \\
\text { region } i \text { and } \\
\text { country } \\
j \text { across all } \\
\text { sectors }\end{array}$ \\
\hline
\end{tabular}

or, equivalently:

The first term on the right-hand of Equation A9 measures the difference in the growth of GDP per worker due to differences in the sectoral employment shares between region $i$ and country $j$, under the hypothesis that the relative GDP per worker of each sector and its growth rate are the same in both the region and the country (i.e., $\pi_{k i}=\pi_{k j}$ and $g_{p w, k i}=$ $\left.g_{p w, k j}\right)$. As the differences in sectoral employment shares are a measure of the industry specialization of the region, this component captures the effects of regional specialization.

The second term measures the difference in the growth of GDP per worker due to differences in the variation of sectoral employment shares between region $i$ and country $j$, under the hypothesis that the relative GDP per worker of each sector is the same in both the region and the country $\left(\pi_{k i}=\pi_{k j}\right)$. As the differences in sectoral employment shares are a measure of the industry specialization of the region, this component captures the effects of a change in regional specialization.

The third term measures the difference in the growth of GDP per worker due to differences in the relative GDP per worker of each sector between the region $i$ and the country $j$, under the hypothesis that the employment share and the growth of GDP per worker of each sector are the same in both the region and the country $\left(E_{k i} / E_{i}=E_{k j} / E_{j}\right.$ and $\left.g_{p w, k i}=g_{p w, k j}\right)$.

Finally, the forth term measures the difference in the growth of GDP per worker due to differences in the sectoral growth of GDP per worker between the region $i$ and the country $j$, under the hypothesis that the employment share of each sector is the same in both the region and the country $\left(E_{k i} / E_{i}=E_{k j} / E_{j}\right)$. 
The third and the forth terms, therefore, measure the difference in the growth of GDP per worker due to a weighted average of differences in either the level or the growth of GDP per worker across all sectors. Taken together, these two latter components capture the effects of differences in average productivity growth.

By replacing A9 into A5, one obtains:

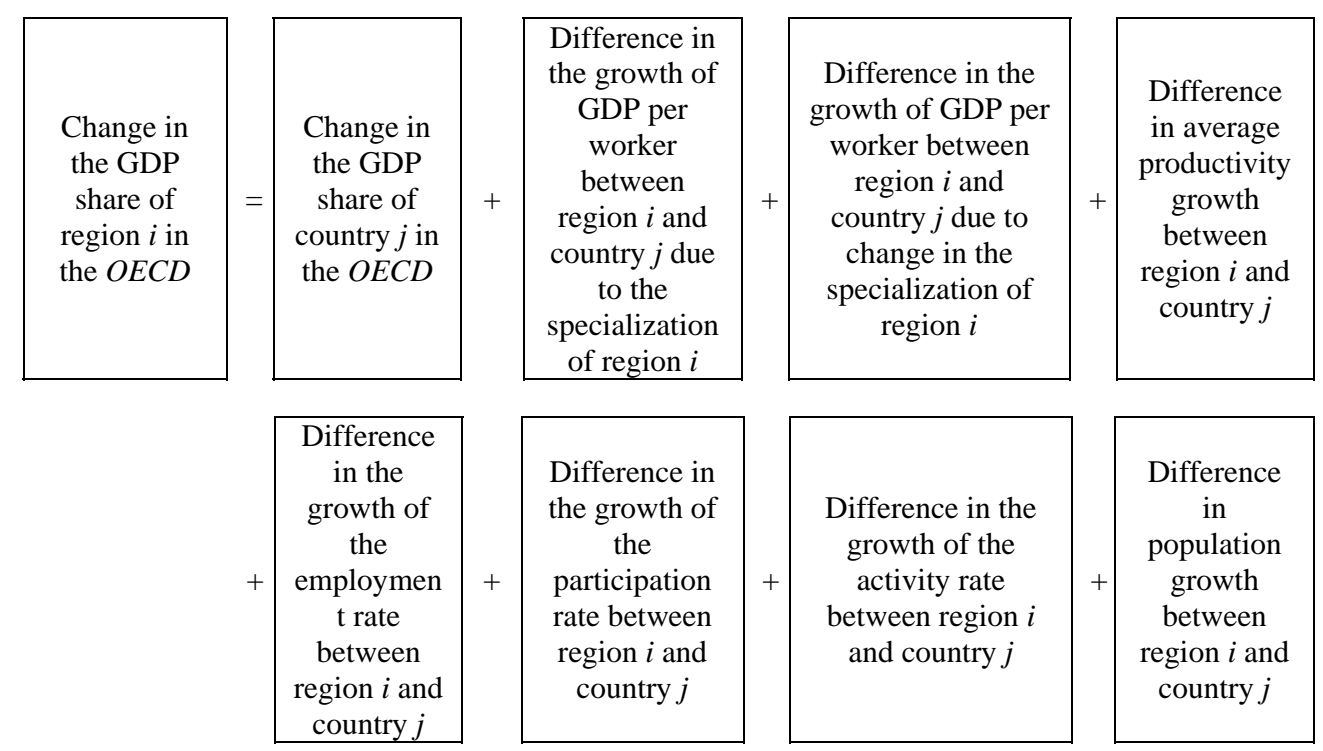

Figure 1 in the body text illustrates the different steps of the above decomposition with the help of a numeric example. 